Preprints of the

Max Planck Institute for

Research on Collective Goods

Bonn 2016/2

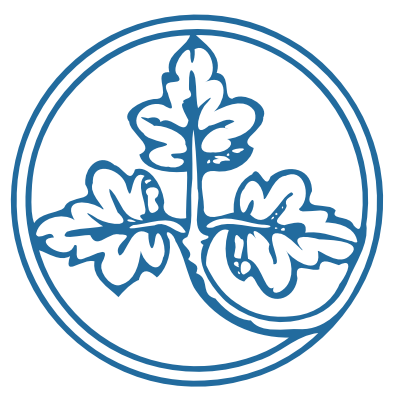

Stability of risk attitudes and media coverage of economic news

Franziska Tausch

Maria Zumbuehl

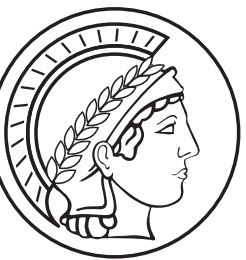




\section{Stability of risk attitudes and media coverage of economic news}

Franziska Tausch / Maria Zumbuehl

February 2016

Max Planck Institute for Research on Collective Goods, Kurt-Schumacher-Str. 10, D-53113 Bonn http://www.coll.mpg.de 


\title{
Stability of risk attitudes and media coverage of economic news
}

\author{
Franziska Tausch, Maria Zumbuehl *
}

February 10, 2016

\begin{abstract}
This paper investigates the impact of exogenous changes in individuals' perceived economic environment on their self-stated risk attitudes by exploiting changes in media coverage of economic news. We use information on risk attitudes from the German Socioeconomic Panel and combine it with data on the average daily frequency of economic news reports during the year and the month preceding the date of the risk attitude elicitation. Using fixed effects regressions we observe effects of both long and short term changes in the media. We find that an increase in economic news in the previous year, irrespective of whether the news are bad or good, is negatively related to individuals' willingness to take risks. An increase in news that are aggregated over the previous month, however, relates to a decrease in risk aversion if the news are predominantly good. The strength of the relations depends on individuals' personal characteristics and personality traits. A positive correlation between bad news coverage and individuals' worries suggests that changes in risk perception may mediate the relation between news coverage and risk attitudes.
\end{abstract}

JEL classification: D80, D03

Keywords: media coverage; economic news; stability of risk attitudes; risk perception

*We thank Mediatenor for providing us with the news data. Further, we are grateful to Thomas Dohmen, Christoph Engel, Oliver Himmler and René Schlegelmilch for helpful comments.

Franziska Tausch: Max Planck Institute for Research on Collective Goods, KurtSchumacher-Str. 10, 53113 Bonn, Germany tausch@coll.mpg.de;

Maria Zumbuehl: University of Bern, Schanzeneckstrasse 1, 3001 Bern, Switzerland maria.zumbuehl@vwi. unibe.ch. 


\section{Introduction}

In economic theory it is often assumed that risk preferences are stable personal characteristics. Many empirical studies however find evidence for withinindividual variation in risk attitudes ${ }^{1}$ over time and show that changes in risk attitudes are related to changes in personal economic circumstances or demographics (see e.g. Andersen et al., 2008, Cho et al., 2013, Jung and Treibich, 2014) and changes in the macroeconomic environment (e.g. Bucciol and Miniaci, 2013, Sahm, 2012). The latter are of particular interest for investigating the systematic variation in risk attitudes, since they are likely to be exogenous to the individual, while observable personal changes are often endogenous. Measures for changes in the environment are however mostly captured in long time intervals (yearly or quarter yearly) which makes it challenging to accurately match them with individual risk data that is elicited throughout the year. Also, individuals may not experience all changes in the macroeconomic environment that are captured by measures like the GDP. Utilizing data on media coverage to create a precise measure for the perceived economic environment of an individual allows to overcome the timing and information problems of the conventional measures as the media reaches a broad audience and information on relevant events are promptly broadcasted.

The focus of this paper is on the link between changes in media coverage of economic news and within person changes in self-stated risk attitudes, and more broadly on the question whether changes in the economic environment can explain systematic changes in individual risk attitudes. Economic news are not only a particularly interesting and diverse measure for the perceived economic environment, but they also allow to make a distinction between long lasting and short term effects of the experienced environment. This allows to shed some light on the mechanism that mediates the relation between risk attitudes and news coverage. The media continuously relays information about economic events in a multitude of areas. In contrast to changes in news coverage of other subject areas that are difficult to evaluate or of interest only

\footnotetext{
${ }^{1}$ We distinguish latent risk preferences and measured risk preferences, which we refer to as risk attitudes.
} 
for a subsection of society, changes in the economy affect virtually everyone and an increase in the amount of bad economic news can be interpreted as a worsening of the economic situation that is experienced by the individuals. While several studies focus on how risk attitudes are affected by rare extreme events like the financial crisis (e.g. Guiso et al., 2013) or natural catastrophes (e.g. Hanaoka et al., 2014), economic news have the advantage that they allow to capture more than one event and also provide an inherent metric for weighting the event's significance. In contrast to conventional aggregate economic indexes, news capture more detailed information about the economy that is conveyed to individuals on a daily base. They therefore constitute a continuous and overarching measure for changes in the economy, which allows individuals to infer and regularly update their own individual risk exposure, e.g. income or unemployment risk, from the information they receive.

Empirical evidence suggests that the media may influence individuals' formation of risk beliefs (see Wahlberg and Sjoberg, 2000). In an economic context Garz (2012), e.g., finds that individuals' perception of job security decreases in years with an increase of news coverage about labor market policy. Generally, it is found that the media has an influence on several social and economic outcomes (for an overview see DellaVigna and Ferrara, 2015).

Many previous studies investigate the determinants of risk attitudes using cross sectional data. They show that the spectrum of how people deal with risk is broad and that considerable heterogeneity in risk attitudes among individuals exists (see e.g. Barsky et al., 1997, or Dohmen et al., 2011). Individual attributes are frequently investigated as influencing factors. Empirically confirmed findings are that the willingness to take risks is negatively correlated with being female and positively with income, wealth, height and education (see Donkers et al., 2001, Hartog et al., 2002, Dohmen et al., 2011).

Personal experience is another factor identified to play a role for risk taking behavior. Malmendier and Nagel (2011) find that individuals who experienced periods of low stock market returns report lower willingness to take financial risk, are less likely to participate in the stock market and have lower expectations about stock market returns. Their estimations show that the influence of recent experiences on risk taking behavior is stronger than 
the influence of distant experiences.

A further strand of literature suggests that risk attitudes depend on individuals' emotions at the moment the attitudes are accessed, thus capturing immediate effects. Most relevant for our context is the finding that individuals that are subjected to a treatment which induces an anxious mood are more risk averse as compared to participants that are untreated or are induced a neutral mood (Raghunathan and Pham, 1999, Guiso et al., 2013). In a lab experiment with financial professionals Cohn et al. (2015) show that priming subjects with a financial bust versus a boom scenario leads to significantly lower willingness to take risks in a subsequent experiment. The authors identify fear as the key channel through which this relation is established. From an additional experiment, using unpredictable electric shocks to induce different levels of fear, they conclude that fear per se, irrespective of the priming framework, is negatively related to willingness to take risks. Lerner and Keltner (2000, 2001) find that dispositional fear, which also predicts state fear, is positively related to the risk assessment of causes of death and negatively related to risk taking behavior when deciding about the abatement of a deadly disease.

Due to the cross-sectional nature of the underlying data, the preceding studies are however not well suited to contribute to the understanding of within-individual variation in risk attitudes over time. A few recent studies apply panel data analysis to investigate what factors are related to this variation. One line of research investigates the effects of changes in individuals' personal circumstances. Using the risk measure from the American National Longitudinal Survey of Youth 79, that is hypothetical gambles over lifetime income, Cho et al. (2013) estimate a fixed effects model and show that risk aversion changes with personal economic circumstances. The authors find that an increase in net family income comes along with increased risk aversion. Further, risk aversion increases in the duration of employment or time spent out of the labor force and decreases with the duration of unemployment. Jung and Treibich (2014) observe correlations between self-stated risk attitudes and shocks in income, labor and health using the Japanese Osaka Panel Survey. ${ }^{2}$

\footnotetext{
${ }^{2}$ Another study that does not focus on exogenous shocks but that is still interesting
} 
There are also a few papers that investigate how risk attitudes are related to changes in the general economic conditions. Using different risk attitude measures of the Dutch Household Survey, Bucciol and Miniaci (2013) estimate a fixed effects model and find that individuals are generally more willing to take risk in periods of economic growth and less so in periods of recessions. Business cycle periods are defined based on the time trend in annual variation in real GDP, AEX stock price index and the NVM house price index. Dohmen et al. (2015) investigate the impact of the economic development as measured by the GDP on the willingness to take risks in the Ukraine and Germany. They find a significant positive correlation between the regional GDP growth rate and the self-stated willingness to take risks in both countries. In Sahm (2012) economic conditions are measured on a monthly base by the Index of Consumer Sentiment which is then combined with the risk measure from the Health and Retirement Study. The estimation of a correlated random effects model reveals that risk tolerance is significantly positively related to the Index of Consumer Sentiment.

For our analysis we combine daily economic news data from the media research institute Media Tenor with survey data from seven waves of the German Socioeconomic Panel (SOEP) on individuals' self-stated willingness to take risks. We tailor our news measures to the date of the SOEP interview on which the risk attitudes are assessed. Forming a moving average of daily economic news reports in the year preceding the risk attitude elicitation we investigate whether long lasting exogenous changes have effects on individuals' self-stated risk attitudes. At the same time we take short term changes in news coverage into account by including the deviation between the yearly news measure and the moving average of the number of news reports in the month before the risk attitude elicitation in the analysis. On top of being precise in the time dimension the media data set allows us to go into more depths with respect to the type of news that are broadcasted. Each recorded

for the discussion of the stability of risk attitudes is Brachert and Hyll (2014). Using panel data from the German Socioeconomic Panel (SOEP) they find that entering into self-employment is associated with a relative increase in the willingness to take risks. Also using data from the SOEP Hetschko and Preuss (2015) e.g. find that becoming unemployed decreases the willingness to take risks, but that this effect is transitory. 
news item is coded as being either good, bad or ambiguous news. Accordingly, we create short and long term measures for the daily average of each of these types of news.

Our analysis reveals that a part of the within-individual variation in risk attitudes over time can be explained by changes in media coverage of economic news. Making use of the panel structure of our data we estimate the impact of bad, good and ambiguous economic news on the willingness to take risks with a fixed effects regression, focusing on the absolute increase in the number of news items. We find that irrespective of their valuation news are negatively related to individuals' willingness to take risk in the long run. When considering short term changes the same holds for bad and good news reports, while for ambiguous news the relation is insignificant. The strength of the adjustment of risk attitudes resulting from long lasting changes in news depends on individual demographics and personality traits. Our results reveal that the long term news measures are better predictors of changes in risk attitudes than the short term measures. Using the short and long-term news measures in combination with the conventional GDP measure for macroeconomic shocks to explain variation in risk attitudes yields that news have explanatory power on top of GDP. This speaks for their precision in capturing experienced previous changes in the economic environment. The short term findings appear not to be driven by media induced changes in mood. Using one month short term measures explains our model better than using one week or two days measures. Instead, we suggest another channel through which news might influence risk attitudes. We show that negative news coverage is related to an increase in perceived risk, which we proxy by individuals' worries about job security, the economic development and the economic situation. After investigating the effects of an absolute increase in news items by valuation, we finally turn to investigate the effects of the relation between good and bad news. So far the results point out that an increase in good news, very much like an increase in bad news is related to a decrease in willingness to take risks. However, the reaction to news coverage might not depend solely on the mass of good and bad news items, but also on their ratio. We thus additionally analyze the nonlinear relation between news 
and risk attitudes by aggregating the news and controlling for the ratio of good and bad news. We find that with a short term news measure the relation between news and risk attitudes is negative when bad news predominate but turns positive when good news predominate. No such change in the direction of the relation is found when considering the long-term measure.

In conclusion, our results show that media coverage of economic news affects individuals' economic risk perception and their self-stated willingness to take risks. The findings are important to understand within individual variation in risk attitude measures over time, as they show that it is at least partly systematic. The exposure to economic news in the previous year is more important for explaining changes in risk attitudes as compared to the recent exposure. Our raw data indicates that on most days news show more negative than positive economic reports. In these situations the valuation of the broadcasted news appears to be irrelevant - more news are always related to a decrease in the willingness to take risks, irrespective of the considered time horizon. In exceptional situations in which good news predominate more news in the short term may however be associated with an increase in the willingness to take risks.

The remainder of this paper is structured as follows. Section 2 introduces our data and explains the choice of the main variables. In section 3 we introduce the empirical strategy and discuss the results. Section 4 concludes the paper.

\section{Data Description}

To address the question whether within-individual variation of risk attitudes is systematically related to economic news coverage, we construct a panel data set combining information from the German Socio-Economic Panel (SOEP) and information on economic news coverage provided by the media research institute Media Tenor. 


\subsection{Risk Attitudes and Risk Perception}

The German Socio-Economic Panel (SOEP) is a large longitudinal representative panel data set (for details see Schupp and Wagner, 2002, Wagner et al., 1993). Starting in the year 2004, seven waves of the SOEP contain a question on the general risk attitude of the respondents. The respondents are asked to assess their willingness to take risks on a 11 point scale, from 'not at all willing to take risks' to 'very willing to take risks'. The survey question is experimentally validated and found to be a good predictor for a number of risky decisions (see Dohmen et al., 2011). For the years that are included in our analysis, the standard deviation of self-stated risk attitudes across individuals amounts to 2.01 while the within-individual standard deviation is 1.41. Given the relatively high within-individual variation, an investigation of whether changes are systematic or pure measurement error suggests itself.

In order to obtain more insights about the mechanism that determines the relation between news coverage and risk attitudes, we make use of another item in the SOEP that elicits to what extent respondents are concerned about various issues. The areas that are relevant for our analysis are the respondent's economic situation and job security as well as the general economic development. The respondents answer on a three points Likert scale with the choices 'not concerned at all', 'somewhat concerned' or 'very concerned'. We use these questions on worries as proxies for individuals' risk perception in the different areas.

The SOEP further contains a variety of personal and household information that we use as control variables. We include information on whether a child below age sixteen is part of the household, the employment status, household income (adjusted by CPI and the size of the household ${ }^{3}$ ), marriage status and health status. Tables 1 and 2 provide detailed information on the data that we use for our main analysis, as well as additional background information that is constant over time (such as gender or year of birth) and that can therefore only enter fixed effects regressions through interactions.

\footnotetext{
${ }^{3}$ The data appendix, Section A.1, provides more detailed information on the construction of the income variable.
} 


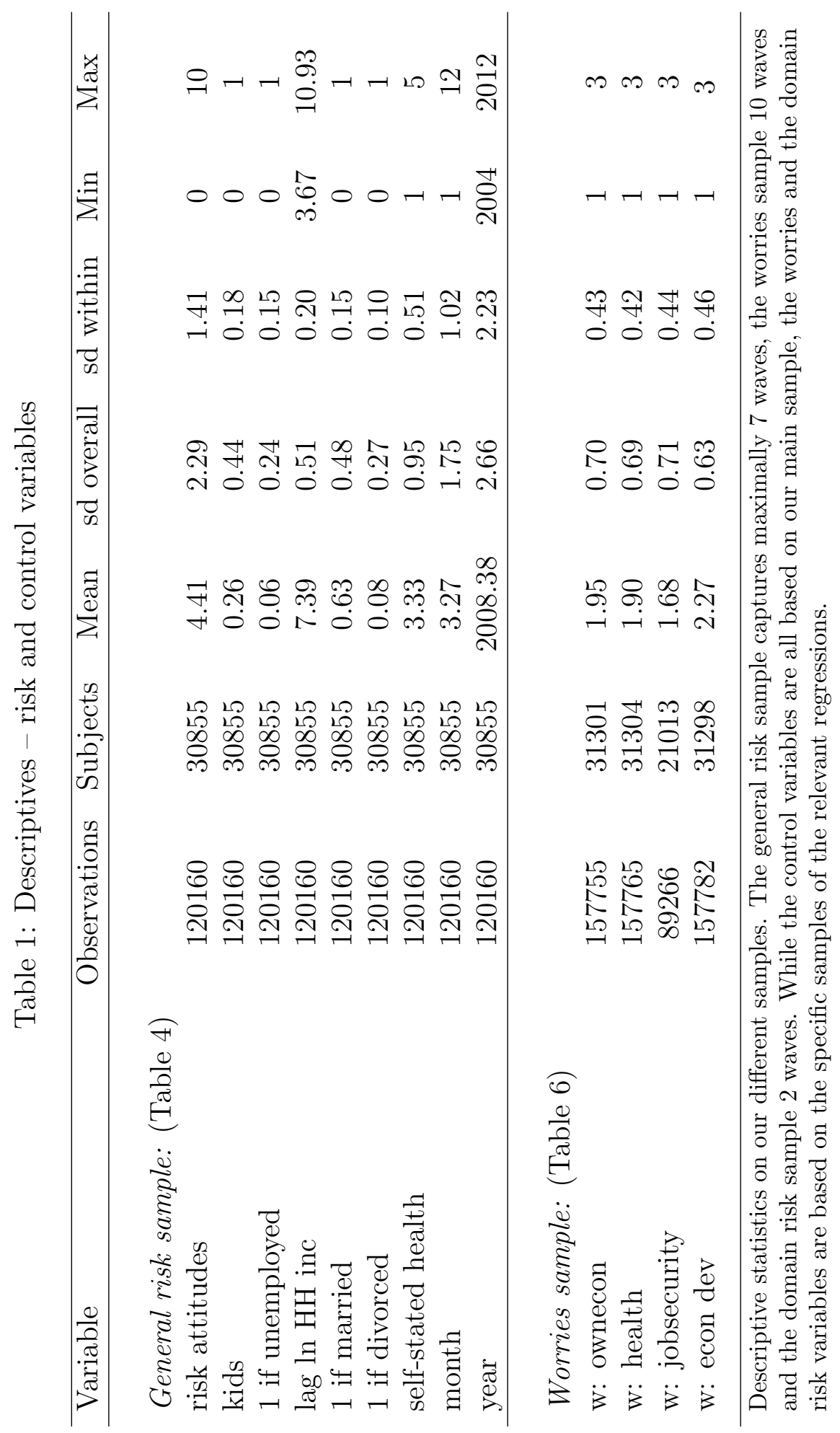


Table 2: Descriptives - demographics and personality traits

\begin{tabular}{lccccc}
\hline Variable & Mean & sd & Min & Max & Subjects \\
\hline female & 0.52 & 0.50 & 0 & 1 & 30855 \\
birth year & 1959.14 & 18.37 & 1905 & 1994 & 30855 \\
education & 12.21 & 2.71 & 7 & 18 & 29383 \\
Big5 O & 4.44 & 1.15 & 1 & 7 & 24771 \\
Big5 C & 5.84 & 0.89 & 1 & 7 & 24757 \\
Big5 E & 4.80 & 1.08 & 1 & 7 & 24827 \\
Big5 A & 5.40 & 0.91 & 1 & 7 & 24829 \\
Big5 N & 3.90 & 1.14 & 1 & 7 & 24837 \\
\hline
\end{tabular}

Descriptive statistics on our main sample. The Big 5 were elicited in 2005 and 2009. For individuals that took part in the elicitation in both years we form the average of the two values.

\subsection{News Coverage}

The news coverage data are provided by the media research institute Media Tenor. The institute analyzes TV news reports as well as newspaper and magazine articles on a diverse range of topics by applying media content analysis. The evaluation is done by professionally trained analysts who identify and categorize on a daily basis each report according to a set of criteria, among others its content and valuation. ${ }^{4}$

Our analysis focuses on news coverage of economic topics in the following leading German newscasts and newspapers: ARD Tagesschau, ARD Tagesthemen, RTL Aktuell, ZDF heute, ZDF heute journal and Bild-Zeitung. ${ }^{5}$ More specifically, we make use of the information on the daily number of news reports in the topic group 'economic situation/economic policies', to which

\footnotetext{
${ }^{4}$ http://www.mediatenor.com

${ }^{5}$ For more detailed information on the different news see their respective websites: http://intern.tagesschau.de/sendungen/tagesschau/; http://intern.tagesschau.de/sendungen/tagesthemen/; http://www.rtl.de/cms/news/rtlaktuell.html; http://www.heute.de/; http://www.zdf.de/heute-journal/heute-journal5989562.html; http://www.bild.de/. We exclude the news coverage data of the weekly journals Focus and Spiegel as the exact day on which individuals are exposed to the journal content is unknown.
} 
we will from now on refer to as 'economics'. ${ }^{6}$ Our media data covers daily reports between January 1, 2001 and August 31, 2012. Media Tenor further provides information on the valuation of the report. The valuation indicates whether the discussed economic topic is in a bad, good or in an ambiguous context. A judgmental representation (bad, good) is existent if the topic is mentioned in a positive or negative context, or if circumstances are reported in words that have a clear positive or negative meaning according to general understanding. Only clearly identifiable valuations are coded as bad or good; news without clear judgment are coded as ambiguous.

\subsection{Combined data set}

While the news coverage information is available on a daily basis, we also know the date of the SOEP interview for each participant. We can thus link the two data sets on the exact date. We construct moving averages of the daily number of economic news reports during the year (364 days) and the month (28 days) preceding the day of the SOEP interview. For the analysis we combine the long-term yearly news measure with a short term deviation measure that is the difference between the monthly and the yearly moving average in news. That way we can capture long-term developments in news coverage as well as rather immediate changes in our analysis.

Table 3 provides information on observation numbers, means and standard deviations of both, the year and the month measure for negative, ambiguous and positive news in our regression sample. Overall, the average number of good news reports is relatively small. For the yearly news measure the average of good news reports is 2.58, whereas ambiguous and bad news are more frequent, with an average daily number of 4.71 and 4.44 news reports respectively. Also the variance of good news reports is lower with 0.48 than those of ambiguous and negative reports (0.63 and 0.78 respectively). For

\footnotetext{
${ }^{6}$ Each news report is further classified into subtopics of economics. One report can be classified as several of the subtopics, but for each report one main topic is defined. In order to avoid a biased representation on news coverage due to multiple classification we focus on those observations that are evaluated to be the main topic of the underlying news report. An overview of all subtopics in economics and the according daily average number of reports and their valuation are reported in Appendix A.
} 


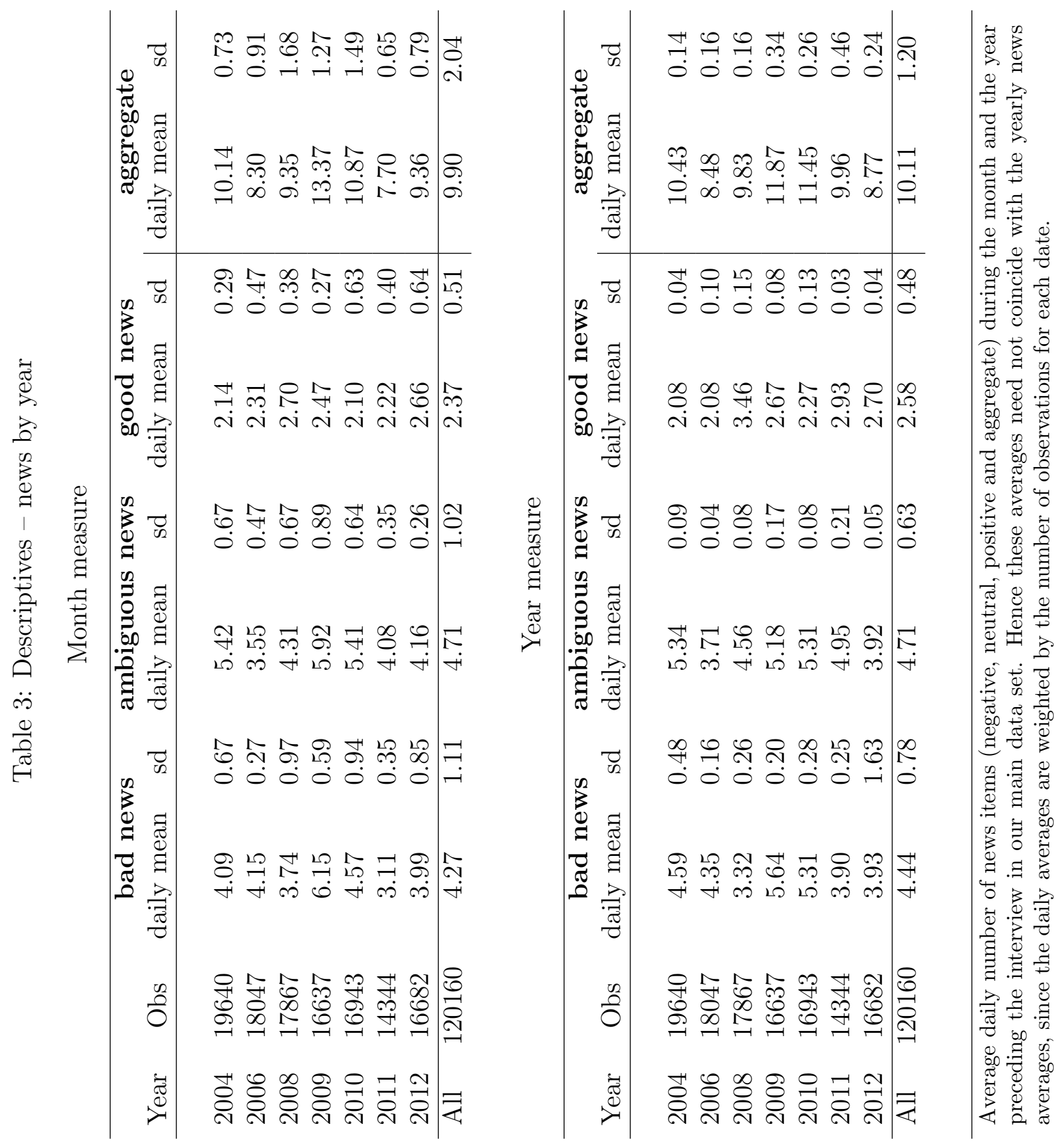


the monthly news measure qualitatively the same differences are observed. However, the variance of ambiguous and bad news is even higher than for the yearly news measures (1.02 and 1.11 respectively), while the variance of good news is very similar for both measures ( 0.51 for the yearly news measure). In 2009 with the beginning of the financial crisis, the average bad economic news coverage increased. The number of bad news is high in that particular year with a monthly average of 6.15 reports per day. Also the yearly measure has the highest averages in 2009 and 2010.

Figure 1 shows the variation in the number of economic news reports over time. The two graphs on the top row provide information on the yearly news measure. The left panel displays aggregate news coverage and the right panel divides the news according to their valuation. The second row shows the same graphs for the monthly news measures and the third row those for the deviation measures. The yearly (monthly) news measure has an average aggregated news coverage of approximately 9.01 (9.23) reports per day and a standard deviation of $2.18(2.55) .^{7}$

\section{Results}

\subsection{News Coverage and Risk Attitudes}

To investigate how exogenous changes in individuals' economic environments influence the temporal stability of general risk attitudes we apply a fixed effects (FE) model, making use of the panel structure of our data. We regress the risk attitude measure at different points in time on the three yearly news measures (bad, good and ambiguous) which we combine in the vector $\operatorname{News}_{t^{*}}^{Y}$, the deviations between the yearly and the monthly news measures $\left(\operatorname{News}_{t^{*}}^{M}-\operatorname{News}_{t^{*}}^{Y}\right)$, and a vector of control variables $\left(X_{i t}\right)$ that includes information on personal changes in life and the year and month of the interview. $u_{i}$ denotes an individual fixed effect and $\epsilon_{i t}$ stands for a time

\footnotetext{
${ }^{7}$ These values are based on the complete Media Tenor data set for the time period 2001 to 2012, as is shown in Figure 1. If we take our regression sample instead (as reported in Table 3) where some days are represented several times and others not at all, we get a daily average of 10.11 (9.90) news items with a standard deviation of 1.20 (2.04).
} 
Figure 1: News - year measure, month measure and deviation measure
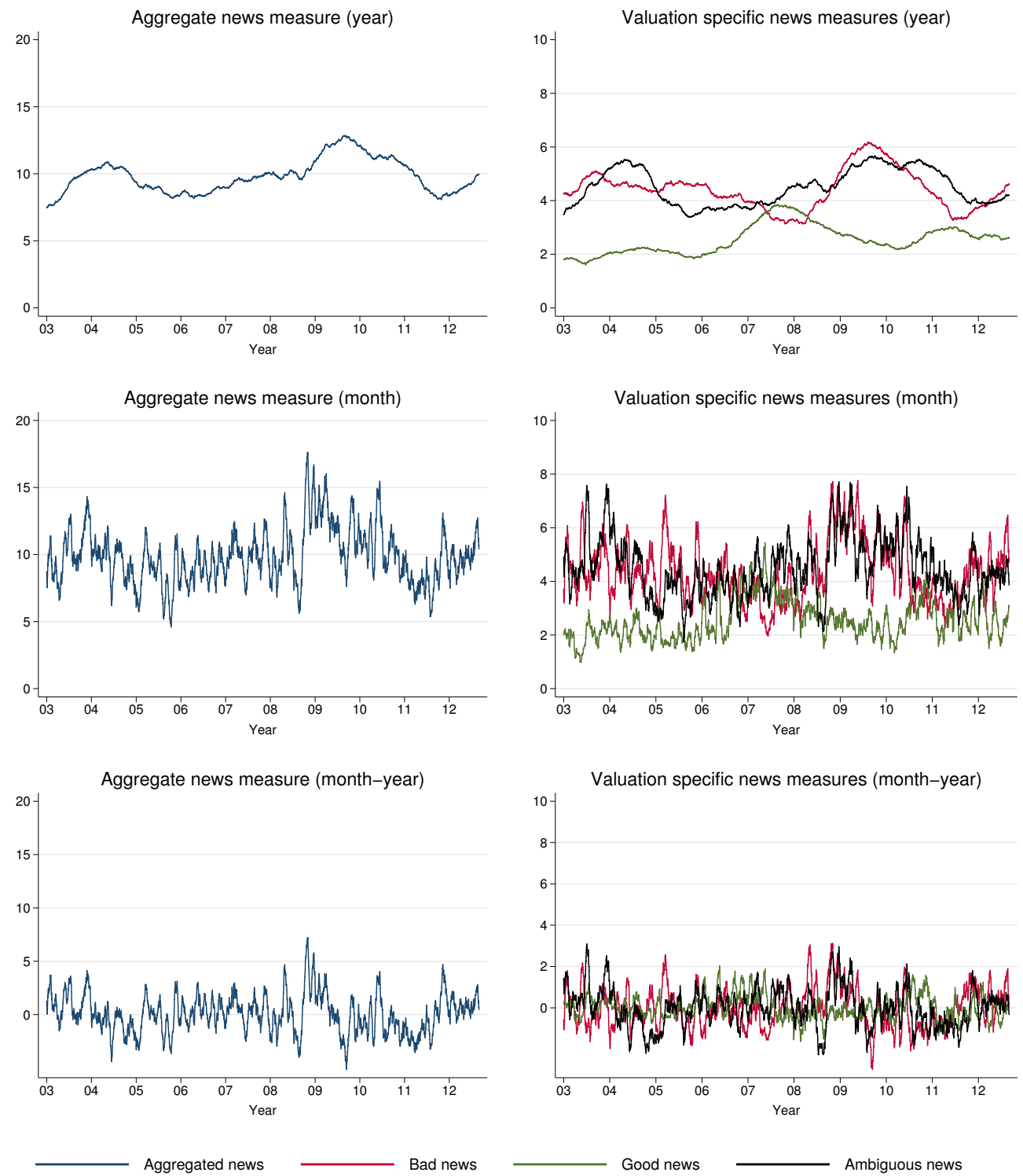

Note: Daily number of news reports averaged over different time-spans. Data for the years 2003-2012 from Media Tenor. 
variant idiosyncratic error term. The personal changes in life include changes in the household composition, in the marital status, in the employment status and the household income, and in the subjective health of the individual.

$$
\text { riskattitude } i t=\alpha+\beta^{\prime} \operatorname{News}_{t^{*}}^{Y}+\gamma^{\prime}\left(\operatorname{News}_{t^{*}}^{M}-\operatorname{News}_{t^{*}}^{Y}\right)+\delta^{\prime} X_{i t}+u_{i}+\epsilon_{i t}
$$

While our news measures do not differ between individuals on any given day, there is heterogeneity in news coverage across the sample within one time unit $t$ since we adjust the news measures to the interview date, rather than using a coarse yearly average.

Table 4 shows the results from estimating the FE model described in equation 1. In Column (4) we estimate the full model; the preceding columns report the results of additional $\mathrm{FE}$ regressions with limited inclusion of the variables of interest. In Column (1) we first regress the risk attitude measure only on personal changes to get a baseline for understanding how much additional within-individual variance can be explained by adding changes in news coverage. Many of the personal changes are endogenous, either directly chosen by the individual (such as getting married) or influenced by earlier decisions of the individual (i.e. those who choose to work on a job with a higher unemployment risk are more likely to become unemployed). While any interpretation of the coefficient other than being a simple correlation is not possible, it is still interesting to briefly look at the relations. Adults are significantly less willing to take risks if there are children below age sixteen living in the same household. Also when getting married individuals are less willing to take risk than if they are not (yet or anymore) married. We do not find any relation between changes in and out of unemployment as well as changes in household income and individual risk attitudes. Finally, changes in reported health are significantly related to within-individual changes in risk attitudes, with better health being associated with a higher willingness to take risks.

We additionally control for the month and the year of the SOEP interview. The control for the timing of the interview within a wave is to deal with heterogeneity in availability of the individuals. More busy individuals could 
Table 4: Risk attitudes - News on willingness to take risks (FE)

\begin{tabular}{|c|c|c|c|c|}
\hline VARIABLES & $\begin{array}{r}(1) \\
\text { risk att. }\end{array}$ & $\begin{array}{r}(2) \\
\text { risk att. }\end{array}$ & $\begin{array}{r}(3) \\
\text { risk att. }\end{array}$ & $\begin{array}{r}(4) \\
\text { risk att. }\end{array}$ \\
\hline year: bad news & & $\begin{array}{c}-0.455 * * * \\
(0.011)\end{array}$ & & $\begin{array}{c}-0.426 * * * \\
(0.013)\end{array}$ \\
\hline year: good news & & $\begin{array}{c}-0.607 * * * \\
(0.017)\end{array}$ & & $\begin{array}{c}-0.602 * * * \\
(0.022)\end{array}$ \\
\hline year: ambiguous news & & $\begin{array}{c}-0.061 * * * \\
(0.010)\end{array}$ & & $\begin{array}{c}-0.101 * * * \\
(0.012)\end{array}$ \\
\hline month: bad news & & & $\begin{array}{c}-0.111 * * * \\
(0.006)\end{array}$ & \\
\hline month: good news & & & $\begin{array}{c}-0.006 \\
(0.011)\end{array}$ & \\
\hline month: ambiguous news & & & $\begin{array}{c}-0.165 * * * \\
(0.006)\end{array}$ & \\
\hline month dev: bad news & & & & $\begin{array}{c}-0.028 * * * \\
(0.008)\end{array}$ \\
\hline month dev: good news & & & & $\begin{array}{c}-0.071 * * * \\
(0.013)\end{array}$ \\
\hline month dev: ambig. news & & & & $\begin{array}{c}-0.008 \\
(0.009)\end{array}$ \\
\hline 1 if children in $\mathrm{HH}$ & $\begin{array}{r}-0.052 * \\
(0.028)\end{array}$ & $\begin{array}{c}-0.063 * * \\
(0.028)\end{array}$ & $\begin{array}{c}-0.057 * * \\
(0.028)\end{array}$ & $\begin{array}{c}-0.062 * * \\
(0.028)\end{array}$ \\
\hline 1 if unemployed & $\begin{array}{c}0.043 \\
(0.035)\end{array}$ & $\begin{array}{c}0.041 \\
(0.034)\end{array}$ & $\begin{array}{c}0.047 \\
(0.034)\end{array}$ & $\begin{array}{c}0.040 \\
(0.034)\end{array}$ \\
\hline lag ln $\mathrm{HH}$ inc & $\begin{array}{c}0.028 \\
(0.024)\end{array}$ & $\begin{array}{c}-0.026 \\
(0.024)\end{array}$ & $\begin{array}{c}0.002 \\
(0.024)\end{array}$ & $\begin{array}{c}-0.026 \\
(0.024)\end{array}$ \\
\hline 1 if married & $\begin{array}{c}-0.096 * * \\
(0.042)\end{array}$ & $\begin{array}{c}-0.108 * * \\
(0.042)\end{array}$ & $\begin{array}{c}-0.100 * * \\
(0.042)\end{array}$ & $\begin{array}{c}-0.108 * * \\
(0.042)\end{array}$ \\
\hline 1 if divorced & $\begin{array}{c}0.015 \\
(0.068)\end{array}$ & $\begin{array}{c}0.006 \\
(0.067)\end{array}$ & $\begin{array}{c}0.011 \\
(0.067)\end{array}$ & $\begin{array}{c}0.005 \\
(0.067)\end{array}$ \\
\hline self-stated health & $\begin{array}{l}0.096 * * * \\
(0.010)\end{array}$ & $\begin{array}{l}0.093 * * * \\
(0.010)\end{array}$ & $\begin{array}{l}0.094 * * * \\
(0.010)\end{array}$ & $\begin{array}{l}0.094 * * * \\
(0.010)\end{array}$ \\
\hline month & $\begin{array}{c}-0.000 \\
(0.005)\end{array}$ & $\begin{array}{l}0.015 * * * \\
(0.005)\end{array}$ & $\begin{array}{c}-0.007 \\
(0.005)\end{array}$ & $\begin{array}{l}0.019 * * \\
(0.005)\end{array}$ \\
\hline year & $\begin{array}{c}-0.028 * * * \\
(0.002)\end{array}$ & $\begin{array}{l}0.013 * * * \\
(0.003)\end{array}$ & $\begin{array}{c}-0.035 * * * \\
(0.002)\end{array}$ & $\begin{array}{l}0.008 * * * \\
(0.003)\end{array}$ \\
\hline Constant & $\begin{array}{l}60.023 * * * \\
(4.746)\end{array}$ & $\begin{array}{c}-17.529 * * * \\
(5.405)\end{array}$ & $\begin{array}{l}75.540 * * * \\
(4.790)\end{array}$ & $\begin{array}{c}-6.922 \\
(5.749)\end{array}$ \\
\hline Observations & 120,160 & 120,160 & 120,160 & 120,160 \\
\hline Number of individuals & 30,855 & 30,855 & 30,855 & 30,855 \\
\hline Adjusted R-squared & 0.004 & 0.045 & 0.032 & 0.046 \\
\hline
\end{tabular}


be harder to reach by the interviewer and thus be interviewed later in the calendar year. The year trend captures age effects as well as a general development over the years that is not captured by the news. ${ }^{8}$ The year trend in this first specification is negative, as can be expected due to the age effect. ${ }^{9}$ The coefficients of personal changes are robust to the inclusion of exogenous changes in the model, as can be seen across the specifications.

In Column (2) we add the yearly news measures for bad, good and ambiguous reports. An increase in the average number of economic news reports, irrespective of the valuation of the news, appears to be negatively related to the willingness to take risks. ${ }^{10}$ One additional bad news item in the daily average is related to a 0.455 points decrease in a person's general willingness to take risks while the according decrease for an additional report of good news is 0.607 . For ambiguous news the coefficient is much smaller with 0.061 , but still highly statistically significant and negative.

In Column (3) instead of the yearly news measures we include the monthly news measures. Here we also find a significant relation between the willingness to take risk and bad and ambiguous news. The coefficients are 0.11 and 0.165 respectively. For good news the relation between self-stated risk attitudes and the monthly news measure is not statistically significant. The explained variance of the model is higher when we include the year measures than when we use the month measures (0.045 versus 0.032).

The analysis in Column (4) finally combines the long and short term measures. We regress the willingness to take risks on the year measures and additionally include the deviations between the year and the month measures. Comparing the full specification to the specification in Column(1) which only includes personal changes, we note a significant increase in explained variance,

\footnotetext{
${ }^{8}$ See Dohmen et al. (2016) for a discussion of age and cohort effects. They show that individuals do become more risk averse over time.

${ }^{9}$ When including the yearly average of news in the analysis, the year trend turns positive. This is strange, but may be an artifact of the correlation between the year trend and economic news over the period we observed.

${ }^{10}$ While it is unlikely that individual risk attitudes have an impact on the national news, we can not completely exclude that a third, independent event (such as a sporting event) leads to an aggregate change of the populations risk attitudes, which influences the real economy and by that also the news. See Dohmen et al. (2006) for such an example.
} 
from an adjusted $\mathrm{R}^{2}$ of 0.004 to 0.046 . We confirm the significant negative relation between the willingness to take risk and news for our long-term yearly news measure, irrespective of the valuation of the news. The coefficient for the short-term deviation is significantly negative for bad and good news, but insignificant for ambiguous news.

We find that both, persistent and temporary changes in news, affect individuals' willingness to take risks. These effects constitute a small but systematic part of the variance in individual risk attitudes over time. ${ }^{11}$

\subsection{Explanatory Value of News}

A conventional proxy for exogenous changes in individuals' environments are yearly changes in the regional gross domestic product. However, the GDP as indicator for changes in the macroeconomic conditions only allows to relate coarse yearly averages to the risk attitude measure. In the following analysis we show the explanatory value that our short and long-term news measures have on changes in risk attitudes on top of the conventional measure for an exogenous change in the economic situation. ${ }^{12}$

Column (1) of Table 5 shows the FE regression of the general risk attitude on GDP change and control variables. A positive change in GDP is associated with a higher willingness to take risks, meaning that in times of economic upswings people are more willing to take risks. This effect is in line with the interpretation of our media coverage data. The coefficient of GDP amounts to 0.070 and the model has an adjusted $\mathrm{R}^{2}$ of 0.024 . Column (2) in Table 5

\footnotetext{
${ }^{11}$ Analyzing the effect of news coverage on risk taking in domains that are unrelated to an economic context is currently not feasible with the SOEP data but very interesting for future research. Respondents of the SOEP were asked about their domain specific risk attitude in the years 2004 and 2009. The questions apply the same wording and scale as the general risk question, but are more specific with respect to the risk taking context. Using the domain specific willingness to take risks instead of the general one yields results for the long-term news measures that are largely in line with our general results. For the short term news measures the interpretation of the results is less clear. These findings are not explicitly discussed here, since the analysis with only two waves of the domain specific risk attitudes is not sufficiently robust to derive meaningful conclusions. The results are available upon request from the authors.

${ }^{12}$ We use statistics on the changes in GDP for all German regions provided by the Federal and State Statistical Offices and adjust GDP for inflation.
} 
Table 5: Risk attitude - News and GDP on willingness to take risks (FE)

\begin{tabular}{|c|c|c|}
\hline VARIABLES & $\begin{array}{r}(1) \\
\text { risk att. }\end{array}$ & $\begin{array}{r}(2) \\
\text { risk att. }\end{array}$ \\
\hline GDP change & $\begin{array}{l}0.070 * * * \\
(0.002)\end{array}$ & $\begin{array}{l}0.015 * * * \\
(0.002)\end{array}$ \\
\hline year: bad news & & $\begin{array}{c}-0.377 * * * \\
(0.015)\end{array}$ \\
\hline year: good news & & $\begin{array}{c}-0.513 * * * \\
(0.026)\end{array}$ \\
\hline year: ambiguous news & & $\begin{array}{c}-0.108 * * * \\
(0.012)\end{array}$ \\
\hline month dev: bad news & & $\begin{array}{c}-0.019 * * \\
(0.009)\end{array}$ \\
\hline month dev: good news & & $\begin{array}{c}-0.050 * * * \\
(0.013)\end{array}$ \\
\hline month dev: ambig. news & & $\begin{array}{c}-0.005 \\
(0.009)\end{array}$ \\
\hline Constant & $\begin{array}{l}49.172 * * * \\
(4.745)\end{array}$ & $\begin{array}{c}0.972 \\
(5.876)\end{array}$ \\
\hline Controls & yes & yes \\
\hline Observations & 120,160 & 120,160 \\
\hline Number of individuals & 30,855 & 30,855 \\
\hline Adjusted R-squared & 0.024 & 0.046 \\
\hline \multicolumn{3}{|c|}{$\begin{array}{l}\text { Note: Fixed effects regressions. 'GDP change' denotes the infla- } \\
\text { tion adjusted yearly changes in the German GDP. The variable } \\
\text { 'years: bad news' stands for the average of bad news reports per } \\
\text { day over the past year, while 'month dev: bad news' captures } \\
\text { the difference between the yearly and the monthly average in } \\
\text { bad news. Controls include children in the HH, unemployed, } \\
\text { HH income, marital status, self-stated health, month and year } \\
\text { of the interview. Robust standard errors in parentheses, }{ }^{*} \\
\text { significant at } 10 \% \text {; }{ }^{* *} \text { significant at } 5 \% \text {; }{ }^{* * *} \text { significant at } 1 \% \text {. }\end{array}$} \\
\hline
\end{tabular}


shows the FE regressions of the individuals' willingness to take risk on GDP change, the yearly news measures and the short term deviations in news. We can observe a doubling in the adjusted $R^{2}$ between Columns (1) and (2), reaching an $R^{2}$ of 0.046 when the news measures are included. This shows that the economic news measures have additional explanatory power on top of the macroeconomic indicator GDP. Moreover, when comparing the adjusted $\mathrm{R}^{2}$ of the regression including GDP and news as independent variables to the same specification but excluding GDP (reported in Table 4 column(4)), we see that adding GDP to the model does not additionally increase the explained variance. The additional predictive power could be due to the higher precision in the measurement of news coverage. Our measures allow to adjust the year moving averages of news reports to the date of the SOEP interview. Further they also capture more than just information about GDP fluctuation as can be seen in the overview of subtopics within the main topic of economic that is displayed in Table A1. Relevant changes in the economic situation can therefore be captured in much more detail by economic news reports as compared to the GDP measure. Finally, while individuals might not notice all the factors which comprise the GDP, they are able to observe all the events that are published or broadcasted in the media. Thus, the news measure captures better what the individuals are exposed to and really experience.

\subsection{Risk perception}

There are several ways how news could potentially influence risk attitudes. One of them is that news coverage has an influence on individuals' risk perception. In this subsection we show how news relate to changes in risk perception that are proxied by information on how worried people are about various issues. The SOEP provides yearly information on how worried individuals are about 1) their own economic situation, 2) their job security (information available only for employed people), and 3) the economic development. The scale ranges from 1 'not worried at all' to 3 'very worried'.

Similar to the first part of the analysis, described in equation 1 we apply 
fixed effects regressions to estimate how changes in individuals' economic environments are related to within-individual changes in worries. Table 6 shows the fixed effects regressions of worries on the long-term and short-term measures of news, as well as personal and time control variables.

Column (1) of Table 6 shows the relation between news and worries about the economic development. Bad news are positively related to individuals' worries, both in the short and in the long run. That means the more bad news individuals encounter over the year, the more worried they are about the economic development. The relation between good news and worries about the economic development is statistically significantly negative, i.e. more good news over the year relate to less worries. For ambiguous news both relations are statistically insignificant. In Column (2) we report FE regressions with worries about the own economic situation as dependent variable. The short and long run effects of bad news are in line with the previous findings. However, both good news measures are insignificant, while ambiguous news are negatively related to the worries in the long run but positively in the short run.

Column (3) reports - for all respondents who are currently in the labor force - how worries about job security relate to changes in news coverage. Here only the year measure of bad news relates significantly positively to job worries. While the positive news measure is not significantly related to the worries, for ambiguous news we find the same pattern as in Column (2): in the short run news are positively related to worries and in the long run negatively.

Overall, bad news are related to an increase in individuals' worries in the short as well as in the long run, while the relations for good news tend to go in the opposite direction or to be insignificant. Ambiguous news instead increase worries in the short run, but lead to a decrease in worries in the long run.

Concerning the personal changes, we find robustly over all regression specifications that changing into a household with a child below the age of sixteen, becoming unemployed, a decrease in household income or a decrease in subjective health relate significantly to an increase in individuals' concerns. 
Table 6: Risk perception - News on worries (FE)

\begin{tabular}{|c|c|c|c|}
\hline VARIABLES & ec. development & $\begin{array}{l}(2) \\
\text { orries about: } \\
\text { own ec. sit. }\end{array}$ & jobsecurity \\
\hline year: bad news & $\begin{array}{l}0.092 * * * \\
(0.003)\end{array}$ & $\begin{array}{l}0.036 * * * \\
(0.003)\end{array}$ & $\begin{array}{l}0.053 * * * \\
(0.004)\end{array}$ \\
\hline year: good news & $\begin{array}{c}-0.127 * * * \\
(0.004)\end{array}$ & $\begin{array}{c}-0.003 \\
(0.004)\end{array}$ & $\begin{array}{c}0.005 \\
(0.006)\end{array}$ \\
\hline year: ambiguous news & $\begin{array}{c}-0.004 \\
(0.003)\end{array}$ & $\begin{array}{c}-0.017 * * * \\
(0.003)\end{array}$ & $\begin{array}{c}-0.027 * * * \\
(0.004)\end{array}$ \\
\hline month dev: bad news & $\begin{array}{l}0.034 * * * \\
(0.002)\end{array}$ & $\begin{array}{l}0.004 * * \\
(0.002)\end{array}$ & $\begin{array}{c}0.001 \\
(0.002)\end{array}$ \\
\hline month dev: good news & $\begin{array}{c}-0.025 * * * \\
(0.003)\end{array}$ & $\begin{array}{c}0.003 \\
(0.003)\end{array}$ & $\begin{array}{c}-0.002 \\
(0.004)\end{array}$ \\
\hline month dev: ambig. news & $\begin{array}{c}-0.000 \\
(0.002)\end{array}$ & $\begin{array}{l}0.010 * * * \\
(0.002)\end{array}$ & $\begin{array}{l}0.012 * * * \\
(0.003)\end{array}$ \\
\hline 1 if children in $\mathrm{HH}$ & $\begin{array}{c}-0.001 \\
(0.007)\end{array}$ & $\begin{array}{l}0.016 * * \\
(0.008)\end{array}$ & $\begin{array}{c}-0.005 \\
(0.009)\end{array}$ \\
\hline 1 if unemployed & $\begin{array}{l}0.073 * * * \\
(0.008)\end{array}$ & $\begin{array}{l}0.199 * * * \\
(0.008)\end{array}$ & $\begin{array}{l}0.122 * * * \\
(0.025)\end{array}$ \\
\hline lag $\ln \mathrm{HH}$ inc & $\begin{array}{c}-0.015 * * \\
(0.006)\end{array}$ & $\begin{array}{c}-0.048 * * * \\
(0.006)\end{array}$ & $\begin{array}{c}-0.013 \\
(0.009)\end{array}$ \\
\hline 1 if married & $\begin{array}{c}0.018 * \\
(0.011)\end{array}$ & $\begin{array}{c}0.005 \\
(0.012)\end{array}$ & $\begin{array}{c}-0.016 \\
(0.016)\end{array}$ \\
\hline 1 if divorced & $\begin{array}{c}0.023 \\
(0.016)\end{array}$ & $\begin{array}{c}-0.013 \\
(0.018)\end{array}$ & $\begin{array}{c}-0.019 \\
(0.024)\end{array}$ \\
\hline self-stated health & $\begin{array}{c}-0.011 * * * \\
(0.003)\end{array}$ & $\begin{array}{c}-0.048 * * * \\
(0.003)\end{array}$ & $\begin{array}{c}-0.039 * * * \\
(0.004)\end{array}$ \\
\hline month & $\begin{array}{c}0.000 \\
(0.001)\end{array}$ & $\begin{array}{c}0.001 \\
(0.001)\end{array}$ & $\begin{array}{c}-0.006 * * * \\
(0.002)\end{array}$ \\
\hline year & $\begin{array}{c}-0.031 * * * \\
(0.001)\end{array}$ & $\begin{array}{c}-0.018 * * * \\
(0.001)\end{array}$ & $\begin{array}{c}-0.037 * * * \\
(0.001)\end{array}$ \\
\hline Constant & $\begin{array}{l}64.247 * * * \\
(1.493)\end{array}$ & $\begin{array}{l}38.208 * * * \\
(1.514)\end{array}$ & $\begin{array}{l}75.700 * * * \\
(2.187)\end{array}$ \\
\hline Observations & 157,782 & 157,755 & 89,266 \\
\hline Number of individuals & 31,298 & 31,301 & 21,013 \\
\hline Adjusted R-squared & 0.105 & 0.023 & 0.040 \\
\hline \multicolumn{4}{|c|}{$\begin{array}{l}\text { Note: Fixed effects regressions. The dependent variables are 'worries about the } \\
\text { economic development' in Column (1), 'worries about the own economic environment' } \\
\text { in Column (2) and worries about the jobsecurity' in Column (3). Only respondents who } \\
\text { are employed are asked about the jobsecurity. The variable 'year: bad news' stands } \\
\text { for the average of bad news reports per day over the past year, while 'month: bad } \\
\text { news' analogously represents the average over the last month. 'month dev: bad news' } \\
\text { captures the difference between the yearly and the monthly average in bad news. '1 if } \\
\text { children in HH' captures if there are any children under } 16 \text { in the household. 'lag ln HH } \\
\text { income' captures the CPI and household } \$ 2 \mathrm{Z} \text { adjusted log household income. Robust } \\
\text { standard errors in parentheses, }{ }^{*} \text { significant at } 10 \% \text {; }{ }^{* *} \text { significant at } 5 \% ;{ }^{* * *} \text { significant } \\
\text { at } 1 \% \text {. }\end{array}$} \\
\hline
\end{tabular}


The results presented in this section indicate that economic news do indeed influence individuals' concerns and thus their risk perceptions. We suggest that risk perception could be a possible channel through which economic news influence individuals' willingness to take risks. At this point however we have to suffice with the suggestive evidence discussed above, since our risk perception variables are too coarsely measured to explain sufficient variance in the willingness to take risk in order to make a structural analysis possible. ${ }^{13}$

\subsection{Affective reaction}

As pointed out in the introduction, empirical studies show that risk attitudes may be influenced by individuals' moods the moment they are assessed. In our context bad (good) economic news may trigger (alleviate) anxiety or fear about the general economic situation and in turn influence risk taking behavior. Such an emotion-driven reaction would suggest that the news coverage just before the risk attitude elicitation has a particularly strong effect on risk attitudes.

We investigate whether the effect of changes in economic news coverage is rather related to news induced emotional changes or whether it is mainly rooted in a long-term adjustment of individuals' economic risk perception. The strong results for the yearly news measures that we show above already indicate that our results are likely not driven by an emotional reaction. However, one could still argue that more prompt measures of news would perform better. To address this concern we construct additional short-term news measures that capture the average daily number of economic news reports during the week and the two days preceding the day of the SOEP interview.

In Table 7 we present the results of fixed effects regressions of risk attitudes on bad, good and ambiguous news measures for different time spans. We include average daily news measures over the timespan of one year, one month, one week and two days. We use standardized values in order to make the

\footnotetext{
${ }^{13}$ The results of the regressions of the risk attitude on worries are available from the authors upon request.
} 
Table 7: Affect - Impact of different time-spans in news on risk

\begin{tabular}{|c|c|c|c|c|}
\hline VARIABLES & $\begin{array}{l}(1) \\
364 \text { days } \\
\text { risk att. }\end{array}$ & $\begin{array}{l}(2) \\
28 \text { days } \\
\text { risk att. }\end{array}$ & $\begin{array}{r}(3) \\
7 \text { days } \\
\text { risk att. }\end{array}$ & $\begin{array}{r}(4) \\
2 \text { days } \\
\text { risk att. }\end{array}$ \\
\hline std. bad news & $\begin{array}{c}-0.408 * * * \\
(0.010)\end{array}$ & $\begin{array}{c}-0.141 * * * \\
(0.007)\end{array}$ & $\begin{array}{c}-0.098 * * * \\
(0.006)\end{array}$ & $\begin{array}{c}-0.085 * * * \\
(0.006)\end{array}$ \\
\hline std. good news & $\begin{array}{c}-0.353 * * * \\
(0.010)\end{array}$ & $\begin{array}{c}-0.005 \\
(0.008)\end{array}$ & $\begin{array}{c}0.014 * * \\
(0.007)\end{array}$ & $\begin{array}{l}0.041 * * * \\
(0.006)\end{array}$ \\
\hline std. ambiguous news & $\begin{array}{c}-0.060 * * * \\
(0.010)\end{array}$ & $\begin{array}{c}-0.199 * * * \\
(0.007)\end{array}$ & $\begin{array}{c}-0.157 * * * \\
(0.007)\end{array}$ & $\begin{array}{c}-0.110 * * * \\
(0.006)\end{array}$ \\
\hline Constant & $\begin{array}{c}-21.155 * * * \\
(5.427)\end{array}$ & $\begin{array}{l}74.364 * * * \\
(4.791)\end{array}$ & $\begin{array}{l}70.849 * * * \\
(4.772)\end{array}$ & $\begin{array}{l}68.662 * * * \\
(4.767)\end{array}$ \\
\hline Controls & yes & yes & yes & yes \\
\hline Observations & 120,160 & 120,160 & 120,160 & 120,160 \\
\hline Number of individuals & 30,855 & 30,855 & 30,855 & 30,855 \\
\hline Adjusted R-squared & 0.045 & 0.032 & 0.021 & 0.014 \\
\hline \multicolumn{5}{|c|}{$\begin{array}{l}\text { Note: Fixed effects regressions of risk on the daily average of economic news during } \\
\text { the year / month / week / } 2 \text { days preceding the interview, and control variables. We } \\
\text { control for having children under } 16 \text { in the household, lagged HH income, being married } \\
\text { and divorced, self-reported health and the month and year of the interview. Robust } \\
\text { standard errors in parentheses, }{ }^{*} \text { significant at } 10 \% ;{ }^{* *} \text { significant at } 5 \% ;{ }^{* * *} \text { significant } \\
\text { at } 1 \% \text {. }\end{array}$} \\
\hline
\end{tabular}

results comparable across the different specifications. This is necessary, as one news item more on average per day over the span of a complete month needs a more fundamental event than a similar increase for just two days.

Going from Column (1) to Column (4) we see that the effects of bad news become smaller in magnitude, the shorter the time frame of the news measure. For good news we observe that while in the long run the effect on the willingness to take risk is negative, it turns positive in the short run. The time span does not seem to play much of a role for the effect of ambiguous news. Overall, the news measure for the shorter time spans perform worse in terms of explained variance. ${ }^{14}$ In general our analyses show that emotion-related

\footnotetext{
${ }^{14}$ If we control for the yearly level of news and investigate the effect of different short-term measures included as deviations from the yearly measures, we get similar results. For good and bad news the monthly deviation has an additional impact, while the deviation of one
} 
effects are not a main determinant of the relation between economic news and risk attitudes.

\subsection{Heterogeneity based on demographics and person- ality traits}

News may affect different types of people to a different extent or even in different ways. Therefore, we investigate how demographics and personality traits influence the relation between changes in economic news coverage and changes in general risk attitudes. We investigate the interaction effects of gender, birth year, education and the "Big Five" personality traits with the news measures. The captured personality traits are openness, conscientiousness, extraversion, agreeableness, and neuroticism. The different traits are in further detail discussed in the Data Appendix. Summary statistics for the demographic and personality trait variables are reported in Table 2.

For each characteristic $\mathrm{v}_{i}$ we estimate a fixed effects regression as follows.

$$
\begin{aligned}
\text { riskattitude }_{i t}= & \alpha+\beta^{\prime} \operatorname{News}_{t^{*}}^{Y}+\gamma^{\prime}\left(\operatorname{News}_{t^{*}}^{M}-\operatorname{News}_{t^{*}}^{Y}\right)+\pi^{\prime}\left(\operatorname{News}_{t^{*}}^{Y} \mathrm{v}_{i}\right) \\
& +\lambda^{\prime}\left(\operatorname{News}_{t^{*}}^{M}-\operatorname{News}_{t^{*}}^{Y}\right) \mathrm{v}_{i}+\delta^{\prime} \mathrm{X}_{i t}+u_{i}+\epsilon_{i t},
\end{aligned}
$$

where $\operatorname{News}_{t^{*}}^{Y}$ is the vector containing the year measures of bad news, good news and ambiguous news. $\operatorname{News}_{t^{*}}^{M}$ is its month equivalent. The timeconstant variable $\mathrm{v}_{i}$ is always normed to the sample average in order to make the interpretation of the interaction terms easier.

Table 8 shows the results of the regression stated in equation 2. Each specification includes the interaction terms with one of the above mentioned demographic or personality variables. Concerning the effect of long-lasting changes in news we find that for higher educated people and those that score high on openness, conscientiousness, extraversion and agreeableness the relation between news coverage and willingness to take risk is more negative for bad news and good news. This means that those individuals react stronger

week or two days has a less or even statistically not significant effect. This does not hold for ambiguous news for which no clear trend can be observed. Results are available upon request. 


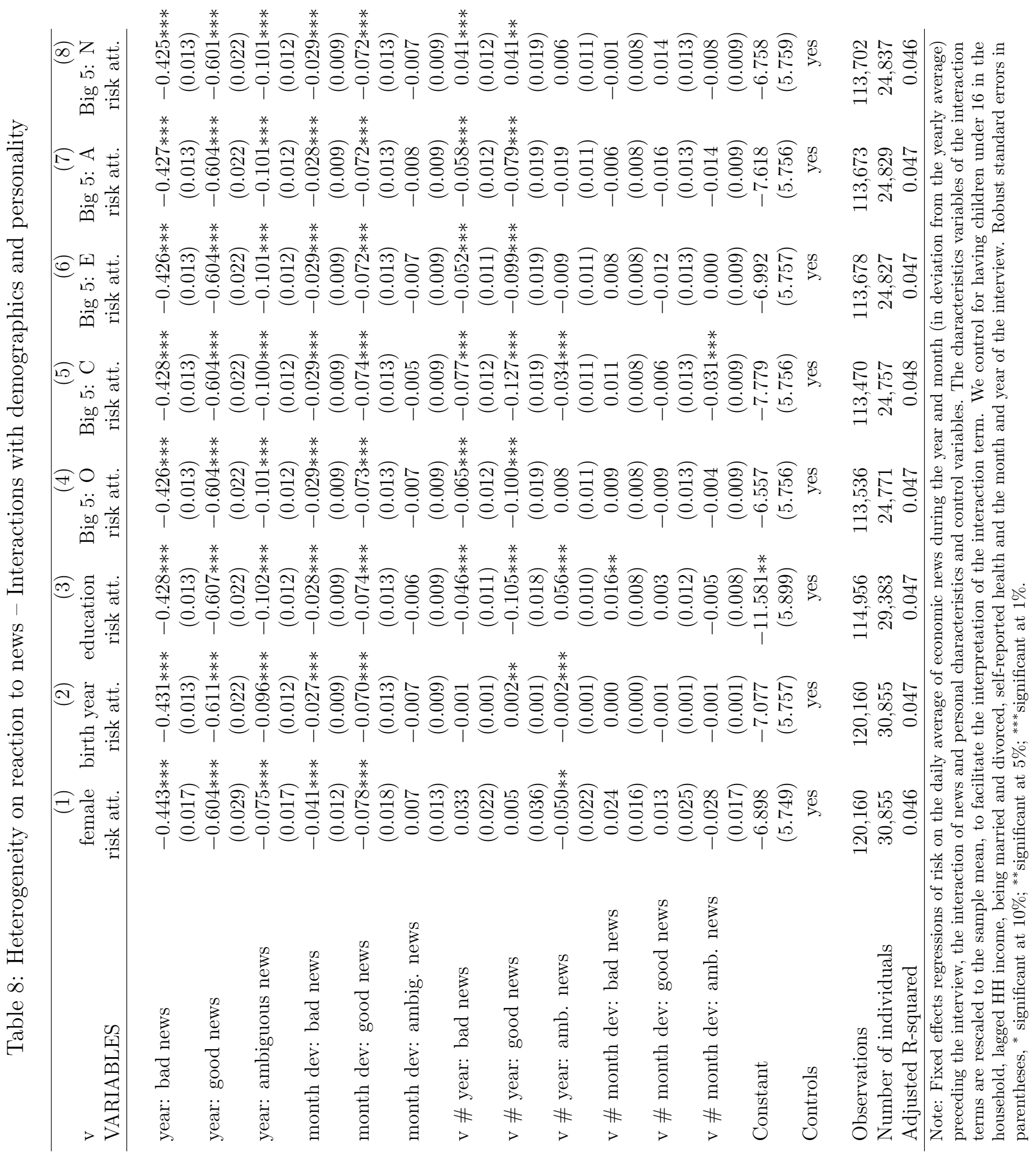


to economic news with respect to their self-stated risk attitudes. ${ }^{15}$ For younger people the effect of good news is less negative. People that score high on the neuroticism scale are a particular case, as they react less strongly on negative news. This might be due to the fact that neurotic people are in general more risk averse and bad news might just confirm what they expected, so that their risk attitudes are not affected. The effect of long lasting changes in ambiguous news is more negative for females, younger people and people that score high on consciousness, whereas it is less negative for higher educated people.

Concerning the effect of short term changes in news we find much less differences in how people's risk attitudes are influenced by news. A short term increase in bad news is less negatively related to the willingness to take risk for higher educated people. For people that score high on consciousness, a short term increase in ambiguous news is more negatively related to risk attitudes.

Overall, while the general results discussed in the previous sections still hold, we find evidence for significant heterogeneity in the magnitude of the impact of long-lasting changes in news on risk attitudes. The magnitude of the effects of short term changes in news instead appears quite stable among individuals with different characteristics.

\subsection{The good news share}

In the previous analysis we only focus on the absolute amount of the different types of news, thus capturing linear effects. However, it is also important to take into account that a given amount of e.g. bad news may have a different effect depending on how many good news are published at the same time. Also, the different types of news measures are correlated. Therefore, we create variables that capture the relation between the good and bad news measures. The share of good news for a particular news measure, share $t_{t^{*}}^{j}$, is specified as

\footnotetext{
${ }^{15}$ Since we do not have individual data on media consumption we can not exclude that the heterogeneity in the strength of the relation between news and risk attitudes is partly due to differences in media consumption behavior that is correlated with some demographics or personality traits.
} 
follows:

$$
\operatorname{share}_{t^{*}}^{j}=\frac{\text { goodnews }}{\text { goodnews }_{t^{*}}^{j}+\operatorname{badnews}_{t^{*}}^{j}} \quad \text { for } \quad j=Y, M
$$

In addition we create an aggregate yearly news measure $\left(\operatorname{news}_{t^{*}}^{Y}\right)$ and an aggregate monthly news measure $\left(\right.$ news $\left._{t^{*}}^{M}\right)$. These measures are the moving averages of the sums of bad, good and ambiguous news in the year and in the month before the risk attitudes are elicited. We then apply a FE estimation of risk attitudes on the particular aggregate new measure, the according share and the interaction of the share and the news measure.

$$
\begin{aligned}
\text { risk-attitude }_{i t}= & \alpha+\beta \operatorname{news}_{t^{*}}^{j}+\gamma \text { share }_{t^{*}}^{j}+\lambda\left(\operatorname{news}_{t^{*}}^{j} \operatorname{share}_{t^{*}}^{j}\right) \\
& +\delta^{\prime} \mathrm{X}_{i t}+u_{i}+\epsilon_{i t} \quad \text { for } \quad j=Y, M
\end{aligned}
$$

With this analysis we investigate how aggregate news perform as predictor of risk attitudes and importantly, whether the predictive power of the aggregate measure depends on the share of good news relative to bad ones. This approach is motivated by the idea that the effect of e.g. bad news may be less strong if individuals are at the same time exposed to a lot of good news that may consequently outweigh the bad news and vice versa. Table 9 Column (1) shows the results of regressing the individuals' risk attitudes on the aggregate year measure and the according share of good news, the interaction of the two and control variables. In line with our previous results we find that aggregate news are significantly negatively related to individuals' willingness to take risks. The interaction of the news measure and the share however is insignificant. This means that the effect of the aggregate yearly news measure on risk attitudes does not depend on the share of good news.

Column (2) reports the same analysis with the aggregate month measure and the month share. Also for this more temporary news measure we find that an increase in aggregate news is related to a decrease in willingness to take risks. For the short term measure however, the interaction term 
Table 9: Good/Bad news ratio - News on willingness to take risks and good news share

\begin{tabular}{lcc}
\hline & $\begin{array}{c}(1) \\
\text { year }\end{array}$ & $\begin{array}{c}(2) \\
\text { month } \\
\text { risk att. }\end{array}$ \\
VARIABLES & risk att. & \\
year: aggregate news & $-0.219 * * *$ & \\
& $(0.042)$ & \\
year: good news share & 0.403 & \\
& $(1.250)$ & \\
yearly news \# yearly share & -0.081 & \\
& $(0.125)$ & $-0.391 * * *$ \\
month: aggregate news & & $(0.015)$ \\
& & $-7.951 * * *$ \\
month: good news share & & $(0.443)$ \\
& & $0.852 * * *$ \\
monthly news \# monthly share & & $(0.045)$ \\
Constant & $44.047 * * *$ & $41.988 * * *$ \\
& $(5.240)$ & $(4.911)$ \\
Controls & yes & yes \\
Observations & & 120,160 \\
Number of individuals & 120,160 & 30,855 \\
Adjusted R-squared & 30,855 & 0.035 \\
\hline
\end{tabular}

Note: Fixed effects regressions. The variable 'years: aggregate news' stands for the average of all news reports per day over the past year. 'year: good news share' captures the ratio between good and bad news during the past year. Controls include children in the $\mathrm{HH}$, unemployed, HH income, marital status, self-stated health, month and year of the interview. Robust standard errors in parentheses, * significant at $10 \% ;{ }^{* *}$ significant at $5 \% ;{ }^{* * *}$ significant at $1 \%$. 
of aggregate news and the share of positive news is positive and highly statistically significant. Thus, the relation of an increase in news and the willingness to take risks depends on the composition of the news. In case news are predominantly good the relation is in fact positive. In our sample the number of bad news during the last month is however higher than the number of good news on $87 \%$ of the days.

Figure 2 displays the graphical interpretation of the relation between additional news in the year or the month before the risk attitude elicitation, their composition, and the willingness to take risks. Panel a) shows the relation between the year moving average and the risk attitude measure for shares of good news ranging from 20 percent to 50 percent. ${ }^{16}$ Clearly, the share does not have an influence on how the two measures are related. Panel b) of the Figure shows the relation between the month measure and the risk attitude measure for shares of good news ranging from 10 percent to 70 percent. Up to a share of 40 percent the relation is negative. As of a share of 50 percent, however, the slope of the regression line turns positive: an increase in the number of aggregate news in the month preceding the SOEP interview is now associated with an increase in the willingness to take risk.

We conclude that while in the long run the constitution of news with respect to their valuation does not influence how news are related to risk attitudes, in the short run the direction of the relation depends on whether good or bad news predominate.

\section{Conclusion}

Self-stated risk attitudes vary over time along with the experiences that individuals make. The media captures a - largely exogenous - part of the environment that individuals experience. In this paper we use media data to examine how the within-individual variation of risk attitudes over time relates to long as well as short term changes in the economic environment.

Using panel data from the SOEP and the media research institute Media

\footnotetext{
${ }^{16}$ The range of shares as well as the range of the amount of news items cover our complete sample distribution.
} 
Figure 2: News and share of positive news

(a) Yearly news measure

\section{Total yearly news and share of positive news}

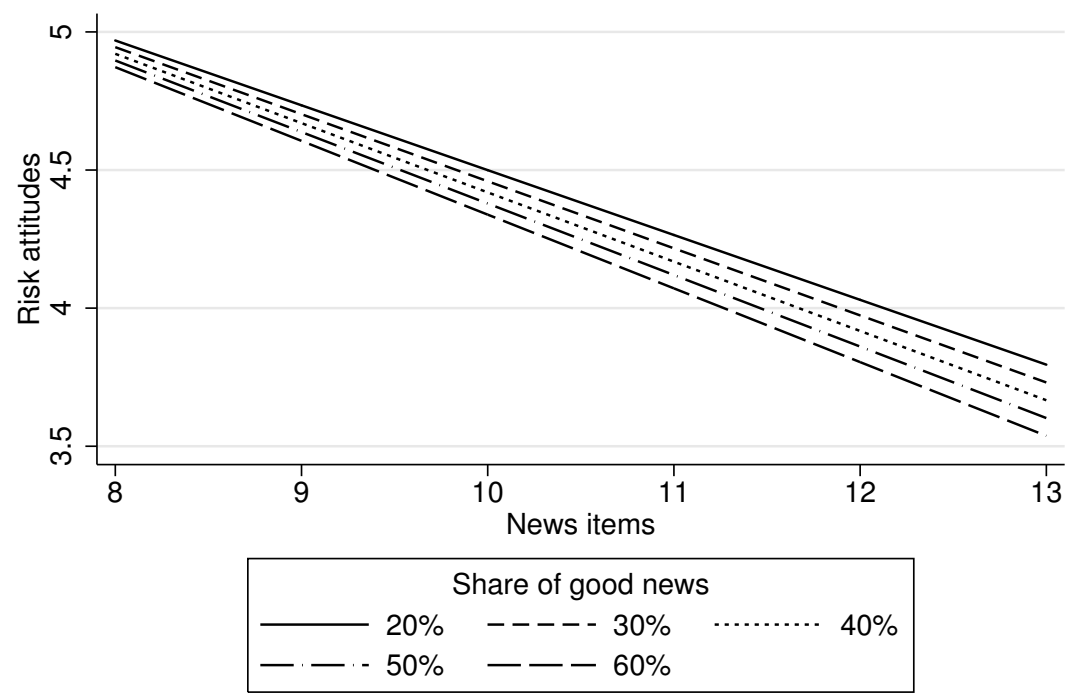

(b) Monthly news measure

Total monthly news and share of positive news

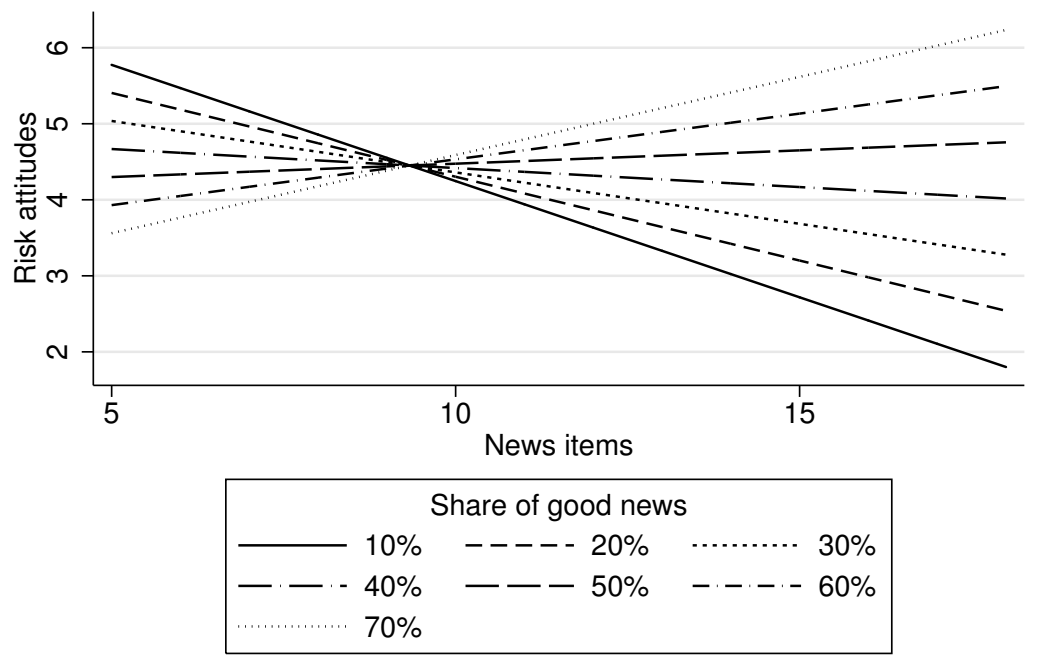

Note: These graphs illustrate the impact of one additional news item per day by the share of good news. The values are computed from the coefficients of the aggregate news and the interaction term of aggregate news and share of good news that we report in Table 9. The share of good news, as well as the amount of news item per day cover the range of values in our dataset. 
Tenor over an eight year span, we find that self-stated risk attitudes vary systematically with the amount of economic news coverage in the year and in the month before risk attitudes are elicited. A high number of bad, good and ambiguous news reports, not taking into account their relative occurrence, is associated with a low willingness to take risks both in the short and in the long run. The exposure to economic news in the previous year is found to be more important for explaining changes in risk attitudes as compared to the recent exposure. We show that in particular the strength of the relations with the long-lasting changes in news depends on individual demographics and personality traits. Using the short and long term news measures together with the conventional GDP measure for macroeconomic shocks to explain variation in risk attitudes yields that news coverage has explanatory power on top of GDP. Economic media coverage appears to be a better predictor of risk attitudes than GDP, which is likely to be due to its higher time precision as well as its ability to capture changes in the economic environment that are in fact experienced by individuals. As our fixed effects regression model is better explained when taking news coverage during the month preceding the risk attitude elicitation into account as compared to the week or the two days before, we may exclude that our results are driven by state emotions induced by the exposure to economic news reports. When aggregating the news and controlling for the share of good news, we find differences in long and short term effects of changes in the media. Looking at the distribution of good and bad news reveals that bad news are generally predominant. In this case the relation between news and risk attitudes is negative, irrespective of the time horizon of the news measure. In exceptional situations in which good news predominate more news in the short term may however be related to an increase in the willingness to take risks, while in the long run the relation is negative.

Our results show that media coverage of economic news affects individuals' self-stated willingness to take risks. A natural next step would be to investigate how changes in self-stated risk attitudes are related to changes in actual risk preferences and importantly, to changes in behavior under risk. Generally, there are three scenarios why individuals may adjust the evaluation of their 
willingness to take risks. 1) Individuals are stable in their behavior and preferences, but they notice a change in others' risk taking behavior and adjust their self-stated risk attitudes, because they rank themselves relative to others. In our setting changes in media coverage affect all individuals and lead to shifts in average self-stated risk preferences which allows us to exclude this point as the driver of our findings. 2) Individuals change their behavior without changing the underlying preferences. They might notice a change in the economic environment, e.g. perceive it as riskier, and therefore behave more cautiously than before. Consequently, the reflection on their actions leads them to adjust their answer to the subjective risk question. 3) Individuals change their actual preferences and therefore change their answer and likely also their behavior. While we cannot verify how individuals' self-stated risk attitudes are related to their underlying preferences, a more important question is whether the systematic changes in risk attitudes that we find translate into changes in actual risk taking behavior. Dohmen et al. (2011) find that the risk attitude measure we use is in fact a reliable predictor of risky decisions. It predicts behavior in a lottery experiment with monetary incentives and is also significantly related to self-reported risky behaviors in different contexts. Our evidence therefore suggests that if risk taking decreases in times of a high media coverage of economic news as suggested by our results, low risk taking behavior may compound the bad economic situation that is presumably the trigger for the increased coverage.

Our analysis further suggests an underlying mechanism that may explain the positive relation between risk attitudes and news coverage. An increase in bad news coverage is related to an increase in individuals' worries about economic issues, pointing at a media induced change in risk perception. Further research is however necessary to clearly identify this mechanism. A finer measure of risk perception e.g. could be helpful to understand the effect that economic news have on individuals' assessment of economic risk exposure. Information about individual media consumption behavior would further allow to control for the extent and the type of news individuals are exposed to, which would allow to more precisely quantify the relation between risk attitudes, the economic environment and risk perception. 


\section{References}

Andersen, S., Harrison, G. W., Lau, M. I., and Rutström, E. (2008). Lost in state space: Are preferences stable? International Economic Review, 49(3):1091-1112.

Barsky, R. B., Juster, F. T., Kimball, M. S., and Shapiro, M. D. (1997). Preference parameters and behavioral heterogeneity: An experimental approach in the health and retirement study. The Quarterly Journal of Economics, 112(2):537-579.

Brachert, M. and Hyll, W. (2014). On the stability of perferences: Repercussions of entrepreneurship on risk attitudes. SOEPpapers 667-2014.

Bucciol, A. and Miniaci, R. (2013). Financial risk attitude, business cycles and perceived risk exposure. Netspar Discussion Paper 02/2013-050.

Cho, I. S., Orazem, P. F., and Rosenblat, T. (2013). Are risk attitudes fixed factors or fleeting feelings? Iowa State University Working Paper No. 13002.

Cohn, A., Engelmann, J., Fehr, E., and Maréchal, M. A. (2015). Evidence for countercyclical risk aversion: an experiment with financial professionals. The American Economic Review, 105(2):860-885.

DellaVigna, S. and Ferrara, E. L. (2015). Economic and social impacts of the media. Working Paper 21360, NBER.

Dohmen, T., Falk, A., Golsteyn, B. H., Huffman, D., and Sunde, U. (2016). Risk attitudes across the life course. Economic Journal, forthcoming.

Dohmen, T., Falk, A., Huffman, D., and Sunde, U. (2006). Seemingly irrelevant events affect economic perceptions and expectations: The FIFA World Cup 2006 as a natural experiment. IZA Discussion Paper No. 2275.

Dohmen, T., Falk, A., Huffman, D., Sunde, U., Schupp, J., and Wagner, G. G. (2011). Individual risk attitudes: Measurement, determinants, and 
behavioral consequences. Journal of the European Economic Association, $9(3): 522-550$.

Dohmen, T., Lehmann, H., and Pignatti, N. (2015). Time-varying individual risk attitudes over the great recession: A comparison of germany and ukraine. Journal of Comparative Economics.

Donkers, B., Melenberg, B., and Van Soest, A. (2001). Estimating risk attitudes using lotteries: A large sample approach. Journal of Risk and Uncertainty, 22(2):165-195.

Garz, M. (2012). Job insecurity perceptions and media coverage of labor market policy. Journal of Labor Research, 33(4):528-544.

Gerlitz, J.-Y. and Schupp, J. (2005). Zur Erhebung der Big-Five-basierten Persoenlichkeitsmerkmale im SOEP. DIW Research Notes No. 4.

Guiso, L., Sapienza, P., and Zingales, L. (2013). Time varying risk aversion. NBER Working Paper No. 19284.

Hanaoka, C., Shigeoka, H., and Watanabe, Y. (2014). Do risk preferences change? Evidence from panel data before and after the great east Japan earthquake. SSRN Working Paper id2543245.

Hartog, J., Ferrer-i Carbonell, A., and Jonker, N. (2002). Linking measured risk aversion to individual characteristics. Kyklos, 55(1):3-26.

Hetschko, C. and Preuss, M. (2015). Income in jeopardy: How losing employment affects the willingness to take risks. Discussion Paper, School of Business \& Economics: Economics 2015/32.

Jung, S. and Treibich, C. (2014). Is self-reported risk aversion time variant? Thema Working Paper n²014-22, Université de Cergy Pontoise, France.

Lerner, J. S. and Keltner, D. (2000). Beyond valence: Toward a model of emotion-specific influences on judgement and choice. Cognition \& Emotion, 14(4):473-493. 
Lerner, J. S. and Keltner, D. (2001). Fear, anger, and risk. Journal of personality and social psychology, 81(1):146.

Malmendier, U. and Nagel, S. (2011). Depression babies: Do macroeconomic experiences affect risk taking? The Quarterly Journal of Economics, $126(1): 373-416$.

Raghunathan, R. and Pham, M. T. (1999). All negative moods are not equal: Motivational influences of anxiety and sadness on decision making. Organizational Behavior and Human Decision Processes, 79(1):56-77.

Sahm, C. R. (2012). How much does risk tolerance change? The quarterly journal of finance, 2(04).

Schupp, J. and Wagner, G. (2002). Maintenance of and innovation in longterm panel studies: The case of the German socio-economic panel (GSOEP). DIW Discussion Paper No. 276.

Wagner, G., Burkhauser, R., and Behringer, F. (1993). The English language public use file of the German Socio-Economic Panel. Journal of Human resources, 28(2):429-433.

Wahlberg, A. A. and Sjoberg, L. (2000). Risk perception and the media. Journal of risk research, 3(1):31-50. 


\section{A Data Appendix}

\section{A.1 SOEP Data}

Risk attitudes are measured in 7 waves of the SOEP, in 2004, 2006, 2008, 2009, 2010, 2011 and 2012. The wording of the question is: "How do you see yourself: Are you generally a person who is fully prepared to take risks or do you try to avoid taking risks? - Please tick a box on the scale, where the value 0 means: 'risk averse' and the value 10 means: 'fully prepared to take risks'. You can use the values in between to make your estimate."

Our proxy for risk perception, worries, is based on yearly repeated questions in the SOEP about the respondents' concerns. We chose the 3 concerns that are related to economics and that are available for the complete time span of our sample. The wording of the question is: "What is your attitude towards the following areas - are you concerned about them?" 'General economic development', 'Your own economic situation' and 'If you are employed: Your job security'. The answer is given in 3 options: 'Very concerned', 'Somewhat concerned' and 'Not concerned at all'.

Among other control variables we include lagged household income in the main regression. We construct adjusted household income as CPI adjusted, log of the household income, after adjusting it for the household size by dividing the total household income by the square root of the number of household members. We use the CPI provided by the German Federal Statistical Office Destatis; the base year is 2010 .

The Big5 personality traits are elicited twice in the SOEP, in 2005 and 2009. The captured personality traits are openness, conscientiousness, extraversion, agreeableness, and neuroticism. The Big Five domains were assessed using the BFI-S psychology questionnaire, a 15-item subset of the NEO-FFI version (see Gerlitz and Schupp, 2005). For the assessment of each personality trait individuals indicate on a seven-point scale to what extent they agree with three statements. Averaging over the three responses yields the score for the particular trait. For each individual we take the average over time of the available information. 


\section{A.2 Media Tenor Data}

Table A1 shows the average number of economic news in the different subtopics, separated by valuation and in aggregation.

Table A1: Subtopics

\begin{tabular}{l|ccc}
\hline Subtopics & \multicolumn{3}{|c}{ Average daily news coverage } \\
& Bad & Neutral & Good \\
\hline \multirow{2}{*}{ national budget } & 1.91 & 1.73 & 1.26 \\
business cycle & 1.76 & 1.50 & 1.56 \\
economic climate & 1.09 & 0.85 & 1.21 \\
economic situation of firms & 0.65 & 0.63 & 0.58 \\
mining & 0.07 & 0.10 & 0.03 \\
agriculture & 0.25 & 0.32 & 0.07 \\
markets & 0.05 & 0.04 & 0.02 \\
labor costs & 0.59 & 0.65 & 0.28 \\
labor market & 1.99 & 2.04 & 1.63 \\
tax policy & 1.41 & 1.76 & 0.88 \\
consumer protection & 0.45 & 0.71 & 0.24 \\
economic demand & 0.57 & 0.54 & 0.85 \\
economic policy & 1.30 & 1.62 & 0.96 \\
national HH policy comparison & 0.13 & 0.12 & 0.08 \\
industrial location & 1.10 & 1.11 & 0.91 \\
\hline aggregated economic news & 4.22 & 4.22 & 2.42
\end{tabular}

\section{A.3 GDP}

Statistics on the changes in GDP per citizen for all German regions for the years 2003 to 2013 are provided by the Federal and State Statistical Offices. The yearly measure is interlinked and adjusted for inflation. Figure A1 shows the GDP change measure for each year between 2003 and 2012 in aggregation for all sixteen regions. Evidently, as with the economic news measures, the harshest decrease can be observed in 2009, the year of the financial crisis. 
Figure A1: GDP change

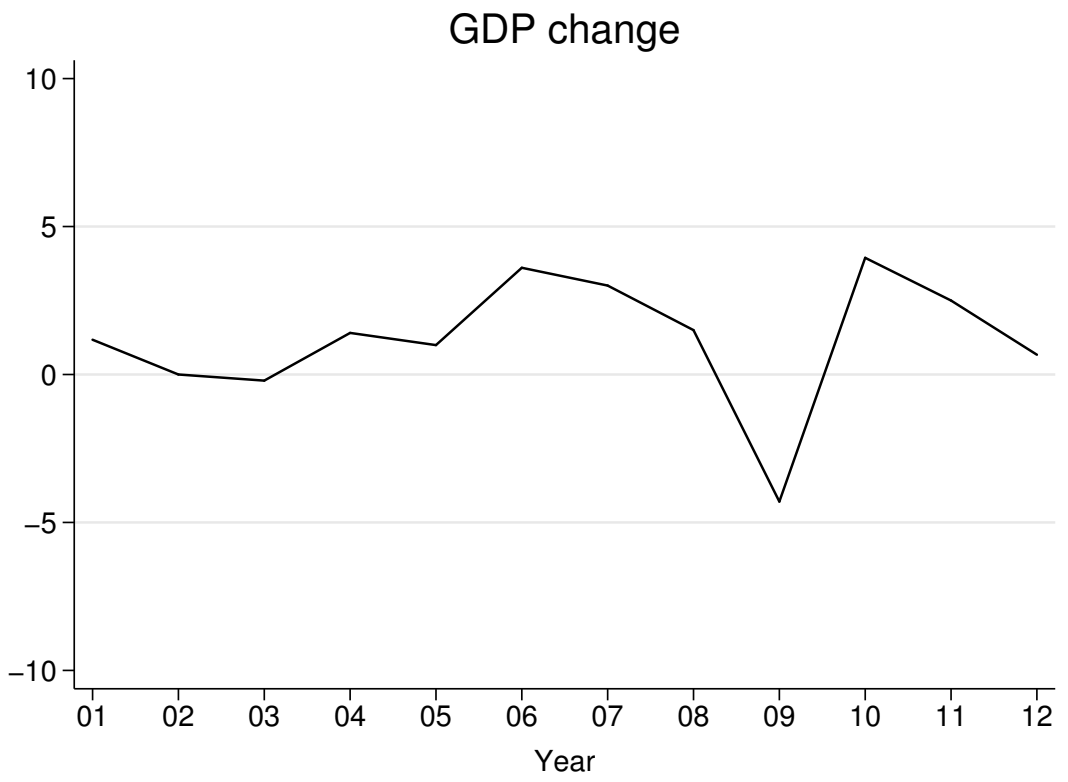

Note: Change in inflation adjusted GDP for Germany. Data for the years 2001-2012 from Destatis. 